conditioning itself is a simple process. This attitude has been responsible for the superficial level of analysis to which Underwood objects. If a more realistic account of the behaviour of humans in conditioning experiments were provided (if we could uncover the more detailed processes at work), then there might be a chance of showing these same processes at work in apparently more complex situations, and thus at last of integrating the various areas of human learning.

N. J. Mackintosh

\section{LABELLED COMPOUNDS}

Proceedings of the Conference on Methods of Preparing and Storing Marked Molecules, Brussels, November 13-16, 1963

Pp. xxiii +1359 . (Brussels: Euratom, 1964. Available from Central Sales Office for Publications of the European Communities, 2 Place de Metz, Luxemburg; and Presses Académiques Européennes, 98 Chaussée de Charleroi, Brussels.) 1,000 Belgian francs.

$\mathrm{T}$ HE preparation of labelled compounds is an absorbing activity for those relatively few people who undertake it professionally; but for the multitude of research workers who use radioactive tracer methods, procurement of a compound labelled specifically for the purpose at hand is a means to an end. If the right compound can be bought at reasonable cost, it usually will be. Nevertheless, the diversity of the requirements of tracer users is now so vast that no organized supply can possibly satisfy them fully, and research workers are necessarily left to their own devices to fulfil their more specialized needs. So producers and users of labelled compounds are related more closely than just as supplier and purchaser: they have many practical problems in common.

These mutual interests were the foundation of the conference on "Methods of Preparing and Storing Marked Molecules", which was the first international gathering on this topic. It was attended by 150 people of varying interests, coming from a dozen or more countries in addition to those of Euratom, who were the hosts and organizers. Clearly it was a most successful conference, which fulfilled a real need for direct personal communication. The Proceedings, which provide a full record of the conference, comprising seven general surveys and sixtythree original papers, should be equally valuable.

The established chemical and biological approaches to labelled compounds are reviewed competently by $\mathrm{L}$. Pichat and J. R. Catch. Many of the other papers break fresh ground, by describing original synthetic methods for particular compounds or groups of them, and syntheses of some forty substances are recorded here for the first time.

The products described are almost exclusively those of biological interest-for example, the tropane alkaloids, chloramphenicol, the actinomycins, gibberellic acid, proteins and peptides; and they are predominantly labelled with earbon-14 or tritium. The papers reflect the present buoyant interest in tritium compounds as biological tracers and the trend towards still higher specific activity and specific chemical labelling with this isotope. There are rather few references to other labelled substances of technical interest outside the biological field.

A useful review by $W$. Herr of radiochemical methods for marking organic molecules emphasizes the merits and the difficulties of these methods. Other papers demonstrate the usefulness of the Wilzbach method when it is applied critically to otherwise intractable problems of labelling, and also its practical limitations.

With the rapid growth of provision and use of radioactive labelled compounds, and the constant trend towards higher specific activities and more critical standards of purity, better control of radiolytic decomposition during storage has become a matter of urgent practical importance. This first open discussion of the subject is therefore of special interest. Excellent reviews of the radiation chemistry of amino-acids and proteins are given by B. M. Tolbert and co-authors, and show the difficulty of relating the results of academic investigations to the stability of labelled compounds observed in practice. An empirical approach to this problem is generally the only one that is immediately useful, and accordingly the practical experience of several observers given in this and other papers is particularly valuable.

The book is excellently edited and printed. It is a large volume of more than 1,350 pages, but roughly half is taken up by English translations of the original texts in other languages. The translations are not always perfect, but they are most serviceable. The editorial staff of Euratom, the publishers and the conference organizers are to be congratulated on getting these proceedings on record less than a year after the event.

W. P. Grove

\section{MATHEMATICAL ANALYSIS}

\section{An Introduction to Mathematical Analysis}

By Prof. Robert A. Rankin. (International Series of Monographs on Pure and Applied Mathematics, Vol. 43.) Pp. xv +607 . (London and New York: Pergamon Press, 1963.) 80s. net.

DEAL variable analysis is a standard part of the undergraduate course in most university departments of mathematics. It has been so for many decades, and it might be thought that the details of the subject, including method of treatment, are so standard and crystallized as to be almost lifeless. Howover, this is not the case, and a comparison of Prof. Rankin's An Introduction to Mathematical Analysis with some recent American and German books reveals how wide the discrepancy can bo. Prof. Rankin's book is based on lecture courses given over many years at the Universities of Cambridge, Birmingham and Glasgow. It deals rigorously with subjects such as limits, continuity, differentiability, integration and convergence (of series and products), and presents what might be regarded as the traditional British approach to the subject. This approach is a gentle one for the student who has had a good grounding in school and first-year mathematics. It is reasonably down-to-earth and part of the philosophy is the provision at numerous points of suitable examples and exercises. In fact, Prof. Rankin writes in the preface as follows: "These exercises have a threefold object, to test understanding of the preceding theory, to provide practice in carrying out the techniques described, and to encourage imaginative thinking by requiring the student to provide his own examples and counter examples".

There can be no doubt that for the great majority of students the approach of this book is the right one. But how sharp is the contrast with, say, the recent book by Maak on Introduction to Modern Calculus. The latter is a beautifully written book, but the approach is highly sophisticated. Let us trace one aspect of the contrast, namely, the introduction of the trigonometric functions. Both authors use an analytical approach, with no reference to triangles. Maak, however, who directs much attention to sequences, introduces a particular sequence, the limit of which is the arctangent function. $\mathrm{He}$ then introduces inverse functions, and thus defines the tangent function as the inverse of the arctangent. After that the sine and cosine functions emerge in terms of the tangent function (of half the angle). Rankin, while remaining strictly analytical, makes very little use of sequences, and introduces the sine and cosine functions directly in terms of 